\title{
Immunolocalization of the matrix metalloproteinases gelatinase B and stromelysin 1 in human endometrium throughout the menstrual cycle
}

\author{
M. Jeziorska ${ }^{1}$, H. Nagase ${ }^{2}$, L. A. Salamonsen ${ }^{3}$ and D. E. Woolley ${ }^{1 *}$ \\ 'University Department of Medicine, Manchester Royal Infirmary, Manchester M13 9WL, UK; \\ ${ }^{2}$ Department of Biochemistry \& Molecular Biology, University of Kansas Medical Center, Kansas City, \\ KS 66160-7421, USA; and ' ${ }^{3}$ Prince Henry's Institute of Medical Research, PO Box 5152, Clayton, \\ Victoria 3168, Australia
}

\begin{abstract}
Immunolocalization techniques were used to examine the distribution of the matrix metalloproteinases gelatinase B and stromelysin 1 in human endometrial specimens, taken across the normal menstrual cycle. Gelatinase B was produced by glandular epithelial cells for approximately 7 days during the proliferative phase, with polymorphonuclear leucocytes, macrophages and eosinophils providing most of this enzyme at menstruation. There was no evidence that gelatinase B is produced by stromal cells or mast cells during the cycle. Immunoreactive gelatinase B in glandular epithelial cells was greatest during the late proliferative phase and just after ovulation; its presence in glandular secretion and the uterine fluid was optimal during the peri-implantation phase. Gelatinase B was clearly associated with an influx of polymorphonuclear leucocytes, macrophages and eosinophils just before, and during, menstruation. In contrast, immunostaining for stromelysin 1 was much weaker than that for gelatinase B, and was present only around stromal cells and limited to microfocal locations at times coincident with stromal oedema (days 8-10 and 21-22). Both enzymes were widely distributed in specimens just before and during menstruation, and were particularly prominent in connective tissue stroma and vascular basement membranes. Specimens at the early proliferative stage were devoid of both enzymes. The data provide further evidence supporting a role for metalloproteinases in endometrial biology, not only in matrix remodelling during the cycle, but also in glandular secretions potentially relevant to blastocyst recognition and implantation. Our observations emphasize the functional importance of specific cell types and the temporal regulation of gelatinase B and stromelysin I throughout the normal menstrual cycle.
\end{abstract}

\section{Introduction}

Endometriai remodelling is a prime feature of the menstrual cycle reflecting coordinated changes of shedding and regeneration. The regulatory mechanisms involved in this process are complex and poorly understood. The roles of hormones, cytokines and growth factors have been examined (Finn, 1986; Hunt, 1994; Murphy and Ballejo, 1994; Tabibzadeh, 1991), but only recently has the role of degradative enzymes become of interest (Marbaix et al., 1992; Martelli et al., 1993; Rodgers et al., 1993, 1994; Hampton and Salamonsen, 1994; Osteen et al., 1994; Rawdanowicz et al., 1994; Schatz et al., 1994).

The matrix metalloproteinases are commonly associated with degradative changes in connective tissue elements and have been studied in both physiological and pathological conditions (Matrisian, 1990; Woessner, 1991). The metalloproteinases as a group include the collagenases, stromelysins and the gelatinases $A$ and $B$, enzymes which together are capable of degrading virtually all components of the extracellular matrix

*Correspondence.

Received 8 December 1995 such as collagens, proteoglycans and glycoproteins (BirkedalHansen et al., 1993; Murphy and Reynolds, 1993). Gelatinase B (92 kDa gelatinase, matrix metalloproteinase-9: MMP-9), degrades a variety of substrates, but particularly collagen types IV and V (Nagase et al., 1991). It is commonly expressed by macrophages, neutrophils and certain transformed and tumour cells (Morodomi et al., 1992; Jeziorska et al., 1994) and also by human cytotrophoblast from the first trimester (Bischof et al., 1991; Librach et al., 1991).

Stromelysin 1 is commonly expressed by fibroblastic cells and has a broad spectrum of substrates which include proteoglycans, type IV, IX and X collagens, laminin, fibronectin and large tenascin-C (Okada et al., 1986; Nagase et al, 1991; Wu et al., 1991; Siri et al., 1995). Since the metalloproteinases probably play potentially important roles in endometrial remodelling and tissue breakdown, the study reported here examined the immunolocalization of gelatinase B and stromelysin 1 in human endometrium throughout the menstrual cycle. Our observations are presented and discussed in relation to the cellular source and the times of stromal remodelling associated with oedema, decidualization and menstruation. 


\section{Materials and Methods}

Endometrial tissue was obtained at curettage from 77 women with regular menstrual cycles (28-29 days), and no apparent endometrial dysfunction; subjects gave informed consent for collection of the tissue (approved by the Human Ethics Committees at the Monash Medical Centre and the Epworth Hospital, Melbourne). The women had either proven fertility and were scheduled for tubal ligation, or were undergoing testing for patency of the Fallopian tubes. Patients with leiomyomas, endometriosis, or those who had received steroid treatment of any kind during the past year were excluded. Tissue samples were fixed in Carnoy's fixative for $2 \mathrm{~h}$, washed in $70 \%$ ethanol and processed routinely to paraffin wax blocks. Tissue sections were cut at $5 \mu \mathrm{m}$, dewaxed, hydrated, and stained with haematoxylin and eosin for histological dating of the menstrual cycle according to the method of Noyes et al. (1950). Specimens were classified according to an idealized 28 day reproductive cycle and then grouped into early, mid-, and late proliferative phases; early, mid-, and late secretory phases and menstrual phase.

\section{Immunohistochemistry}

Gelatinase B (MMP-9) was demonstrated using the alkaline phosphatase anti-alkaline phosphatase (APAAP) technique with a sheep polyclonal antibody to human gelatinase $B$ derived from the fibrosarcoma HT-1080 cells as described by Ogata et al. (1992). The primary antibody was prepared and rigorously characterized for monospecificity; western blotting tests, as described by Lees et al. (1994) and Tetlow et al. (1993), showed no crossreactivity with the purified metalloproteinases collagenase-1, stromelysin 1 , gelatinase A and matrilysin. The primary antibody of affinity-purified immunoglobulins was used at a dilution of $12.5 \mu \mathrm{g} \mathrm{ml} \mathrm{m}^{-1}$ in Tris-buffered saline containing $10 \%(\mathrm{v} / \mathrm{v})$ rabbit serum. Primary antibody that bound to the tissue section was visualized using rabbit anti-sheep IgG followed by sheep APAAP complex (Dako, Glostrup, Denmark), repeated twice, and using New Fuchsin to produce a red precipitate.

Stromelysin I was demonstrated using a rabbit polyclonal antibody to the purified human enzyme prepared as described by Lees et al. (1994). The primary antibody was checked for monospecificity and crossreactivity with other purified metalloproteinases (Tetlow et al., 1993; Lees et al., 1994). Affinity purified immunoglobulins were used at $7.5 \mu \mathrm{g} \mathrm{ml}^{-1}$ in Tris-buffered saline containing $10 \%$ swine serum, using the same APAAP method as described for gelatinase B, but with swine anti-rabbit secondary antibody and rabbit APAAP (both from Dako, High Wycombe).

Endogenous alkaline phosphatase was blocked with levamisole. Controls included normal sheep or rabbit IgG $(12.5 \mu \mathrm{g}$ $\mathrm{ml}^{-1}$ and $7.5 \mu \mathrm{g} \mathrm{ml}^{-1}$, respectively) and primary antibodies previously adsorbed with an excess of pure antigen (Tetlow et al., 1993). All controls consistently produced no staining of the tissues. All tissue sections were counterstained with haematoxylin and evaluated using a Zeiss Photomicroscope III. Photographs were taken using Ektachrome $160 \mathrm{film}$.
Dual immunolocalization of gelatinase B with specific cell markers

On selected specimens, dual immunofluorescent staining was used to identify the cellular source of gelatinase B, the sheep antibody to the latter being visualized with fluorescein isothiocyanate- (FITC) conjugated rabbit anti-sheep IgG. This immunostaining was combined with each of the following antibodies: (i) rabbit antibody to PMN-elastase, (ii) monoclonal antibodies CD68, KPI and MAC 387 (Dako) to detect monocytes-macrophages, (iii) monoclonal EG1 and EG2 (Pharmacia Ltd, Milton Keynes, Bucks) to detect eosinophils, and (iv) monoclonal anti-mast cell tryptase conjugated directly to alkaline phosphatase (Chemicon International, Harrow, Middlesex). Antibodies (i)-(iii) used to detect specific cell types were visualized using an appropriate goat or donkey second antibody conjugated to Texas Red; for (iv) the alkaline phosphatase was developed using Fast Red substrate which fluoresces red under conventional UV illumination. Controls included relevant non-immune immunoglobulins and consistently produced no background fluorescent staining. The tissue sections were mounted in Immunomount (Shandon, Runcorn, Cheshire), examined and photographed using a Zeiss Photomicroscope III with filter sets for FITC or Texas Red and Fast Red.

\section{Results}

The study was carried out using 77 specimens which represented every stage of the menstrual cycle (Table 1). Gelatinase $B$ was absent from endometrial tissues immediately after menstruation and first appeared in glandular epithelial cells during the mid-proliferative phase. Intracellular staining for gelatinase $B$ became more intense in the apical and Golgi zones of glandular epithelial cells in the late proliferative phase (Fig. $1 \mathrm{a}, \mathrm{b})$. During the secretory phase gelatinase B was observed in both the early and mid-phases, but there was evidence of extracellular secretion into the glandular lumen starting at day 16. A more pronounced secretion was observed on day 17 , and by day 21 most of the enzyme was located in the glandular secretion. On day 23, the enzyme was observed primarily within the glandular secretion and in the cytoplasm of epithelial cells bordering that secretion (Fig. 1c). No staining of the glandular epithelium was detected after day 24 (Fig. Id). Staining for gelatinase B was also observed in the luminal epithelium which lined the uterine cavity, mainly during the early secretory phase, but this appeared a few days later than in the glandular epithelium.

Polymorphonuclear leucocytes (PMNs) present in the vasculature throughout the menstrual cycle consistently stained for gelatinase B (Fig. Ib, d); this staining was especially prominent for those extravascular PMNs observed in the stroma of the late secretory phase and menstruation (Fig. 1e, f). Some monocytes and macrophages also showed immunostaining for gelatinase $\mathrm{B}$, but this was generally much weaker than that for PMNs. The first appearance of extracellular gelatinase $B$ within the stroma was observed 2 days before the onset of, and during, menstruation, usually in association with PMNs (Fig. Ie, f). Pronounced staining for the extracellular enzyme was a common feature of endometrial material from all menstruation samples. 


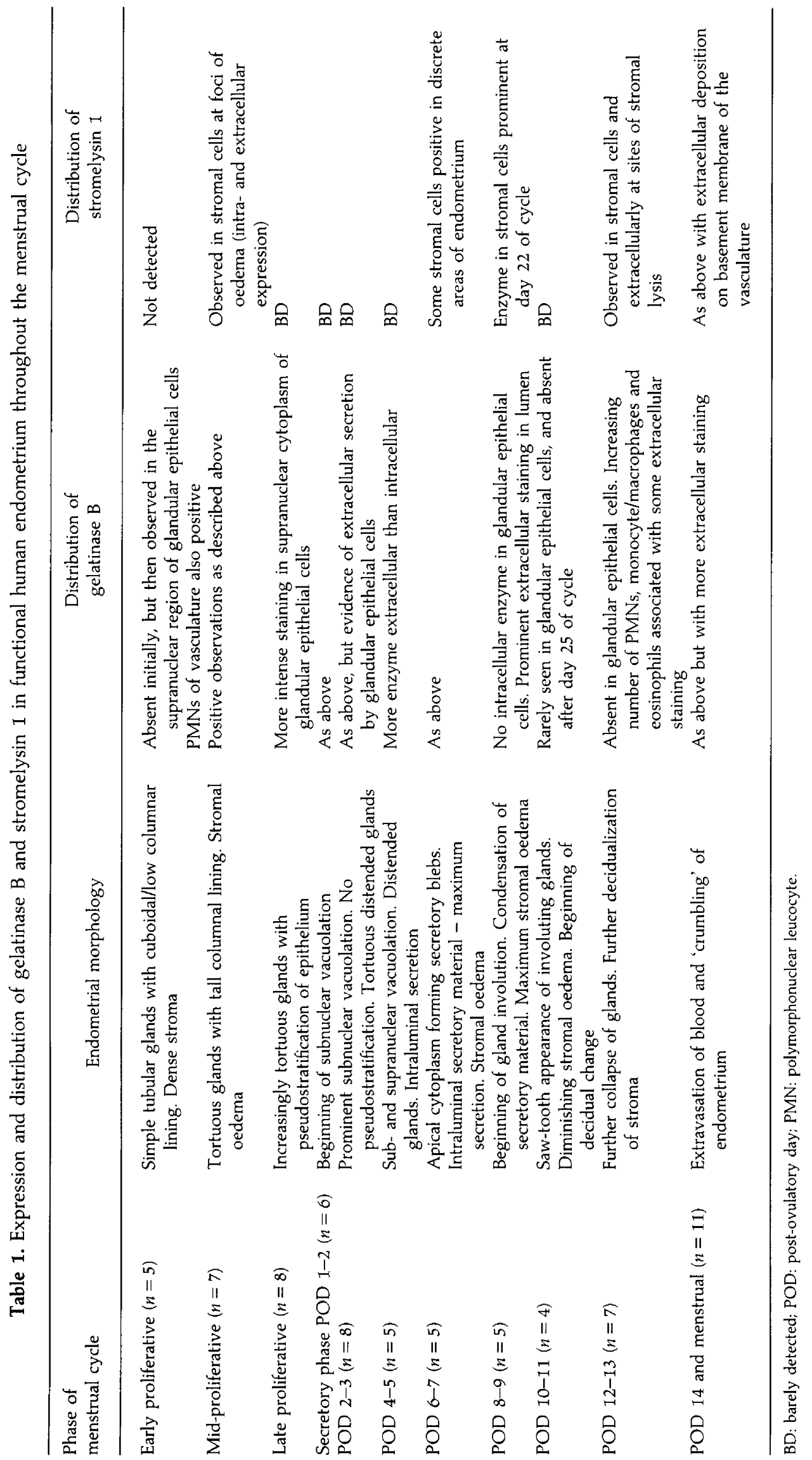


Gelatinase B staining was observed primarily in the functionalis, but occasionally intracellular staining appeared in epithelial cells of typical basalis glands during the secretory phase. Dual immunolocalization techniques were used to identify more accurately the cellular source of gelatinase B during menstruation. Immunoreactive gelatinase B was co-localized with specific cell markers used to identify PMNs, monocytemacrophages and eosinophils (Fig. 2). Since all three migratory cells show an increased distribution just before, and during, menstruation, it would appear that these cells are the major source of gelatinase B in menstrual tissues. However, when extracellular gelatinase $B$ was prevalent during the late
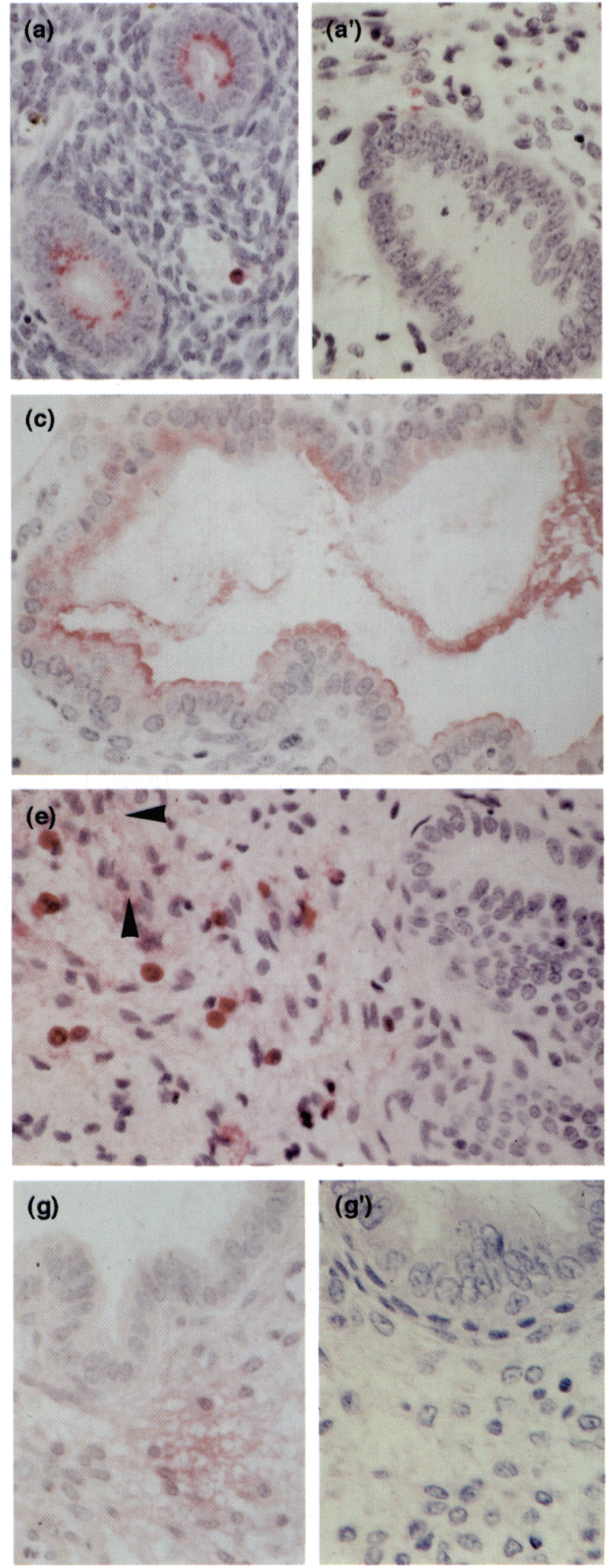
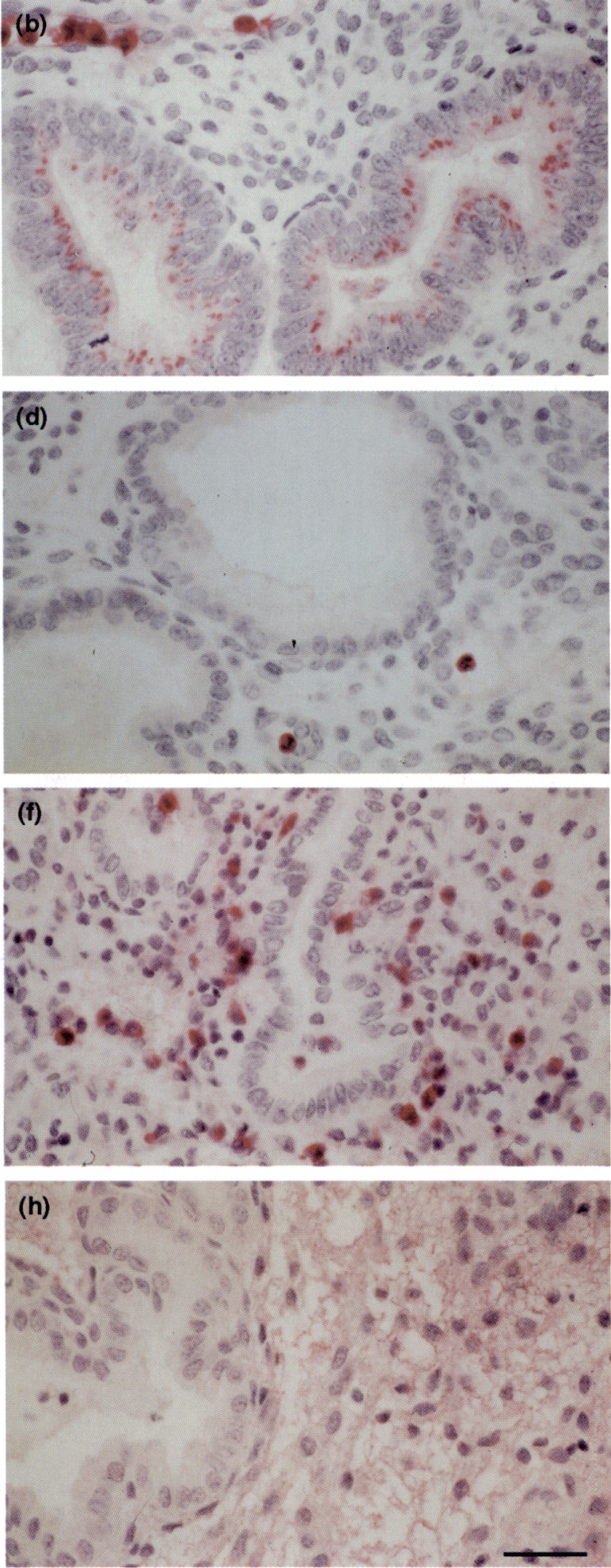
secretory phase and menstruation, relatively few monocytemacrophages were identified with the specific markers CD68 and MAC 387, an observation that suggests that PMNs are the major source of gelatinase $B$ at this time of the cycle. In contrast, the enzyme was not observed in stromal endometrial cells, or in mast cells (Fig. 2 $\mathrm{d}^{\prime}$ ); but in areas showing mast cell activation, as judged by extracellular tryptase, a localized increase of gelatinase B distribution was often noted.

Extracellular stromelysin 1 was observed in the endometrial stroma during the proliferative (days 8-10, Fig. Ig) and secretory (days 21-22) phases, with more pronounced staining 2 days before menstruation (Fig. $\mathrm{Th}$ ) and in the stromal tissue of menstruation specimens. When stromelysin 1 was observed, it was often associated with stromal disruption, usually in microfocal locations. Shortly before the onset of menstruation these foci expanded and subsequently demonstrated a widespread distribution of extracellular stromelysin in menstruation specimens. In contrast to gelatinase B, stromelysin 1 was immunolocalized only in, and around, stromal cells. PMNs, macrophages, mast cells, eosinophils and all epithelial cells were consistently negative for stromelysin $I$ throughout the cycle.

Stromelysin 1 production appeared to correspond to the recognized times of endometrial oedema, that is, days 8-10 and days 21-23 (Table 1 and Fig. 3). Moreover, menstrual tissue specimens often showed immunoreactive stromelysin 1 associated with the basement membrane structures of various blood vessels. In general, the staining intensity and distribution of stromelysin was not as pronounced as that visualized for gelatinase $\mathrm{B}$.

\section{Discussion}

Steroid-induced growth, cellular differentiation and breakdown of the endometrium are prominent remodelling features of the menstrual cycle. The matrix metalloproteinases are a tightly regulated family of enzymes that degrade specific components of the extracellular matrix, and recent reports have suggested that they play important roles in the endometrial remodelling associated with development, blastocyst implantation and menstruation (Salamonsen et al., 1991, 1993; Marbaix et al., 1992, 1995; Matrisian et al., 1994; Osteen et al., 1994; Rodgers et al., 1994). The present study used immunolocalization techniques to examine the distribution of gelatinase $\mathrm{B}$ and stromelysin 1 in human endometrial specimens, including at least two specimens for each day of the menstrual cycle. Gelatinase B production by glandular epithelial cells showed precise, temporal regulation, with immunolocalization starting at about day 7 and extracellular secretion into the glandular lumen beginning on day 15 , reaching a maximum at days $21-23$, and with no further production after day 24 . At present it is uncertain when and how the progelatinase $B$ becomes activated in the glandular secretion, or what substrates the enzyme might recognize. Uterine fluids show temporally related compositional changes in secretory glycoconjugates and in the thickness and composition of the apical glycocalyx of uterine epithelial cells during the peri-implantation period (Aplin, 1991; Aplin et al., 1994). Since gelatinase B secretion is optimal during this peri-implantation phase, it is possible that this enzyme might be functional in processing specific components of the uterine fluid, thereby contributing to the recognition processes required for blastocyst implantation.

The importance of progesterone in the regulation of metalloproteinase expression has been emphasized (Jeffrey et al., 1971; Sato et al., 1991; Marbaix et al., 1992; Martelli et al., 1993; Osteen et al., 1994; Rodgers et al., 1994). Physiological concentrations of progesterone inhibit the release and activities of collagenase, stromelysins and gelatinases $\mathrm{A}$ and $\mathrm{B}$ by human endometrial explants (Marbaix et al., 1992; Osteen et al., 1994) and of stromelysin 1 by endometrial stromal and decidual cells (Schatz et al., 1994). The present study indicates a maximum synthesis of gelatinase B by glandular epithelium during ovulation with its associated high concentrations of oestrogen, whereas the extracellular secretion of gelatinase B is stimulated as progesterone concentrations increase during the early secretory/implantation phase. These observations for gelatinase $B$ are thus in accord with studies in vitro relating to the downregulation of metalloproteinases by progesterone. This situation was not so evident for our observations of stromelysin I production; this enzyme was produced in microfoci by stromal cells during the mid-secretory phase, a time of high progesterone concentration. However, apart from its enhanced distribution at menstruation, in general, the production of stromelysin 1 can be regarded as weak, in agreement with the relatively low or negligible amounts of mRNA encoding the enzyme from human endometrial specimens as reported by Hampton and Salamonsen (1994) and Osteen et al. (1994). Although a functional role for stromelysin 1 in the degradative processes associated with menstruation appears evident, its relative importance in the stromal microfoci during the

Fig. 1. Immunolocalization of gelatinase B and stromelysin I in human endometrium during the normal menstrual cycle. (a) Mid-proliferative phase, day 8. Staining for gelatinase B (red) in supranuclear regions of glandular epithelial cells. (a') Negative control for gelatinase B staining using non-immune sheep IgG instead of primary antibody. Similar tissue location from consecutive section to (b). (b) Late proliferative phase, day 12. Pronounced staining of gelatinase B in glandular epithelial cells and in polymorphonuclear leucocytes (PMNs) and monocytes confined to blood vessels. (c) Mid-secretory phase, day 23 (post-ovulatory day (POD) 9). Apical distribution of gelatinase B in glandular epithelial cells and extracellular gelatinase B in the lumen of the gland. (d) Late secretory phase, day 26 (POD 12). Staining for gelatinase B only in PMNs confined to the vasculature. Note absence of enzyme from endometrial glands. (e) Late secretory phase, day 28 (POD 14). Deep layer of the functionalis. Note disrupted stroma with numerous PMNs and monocyte-macrophages showing intra- and extracellular (arrowheads) staining for gelatinase B. ( $f$ ) First day of menstruation. Disrupted glands and stroma with numerous PMNs and monocyte-macrophages positive for gelatinase B. ( $g$ ) Mid-secretory phase, day 21 (POD 7). Focal stromal distribution of stromelysin 1 (red staining) associated with visible disruption of stroma. ( $\mathrm{g}^{\prime}$ ) negative control for stromelysin 1 staining using non-immune rabbit IgG instead of primary antibody. Similar tissue location from consecutive section to $(\mathrm{g}$ ). (h) Late secretory phase, day 28 (POD 14). Widespread distribution of stromelysin 1 associated with areas of stromal disruption. Scale bar represents $40 \mu \mathrm{m}$. 

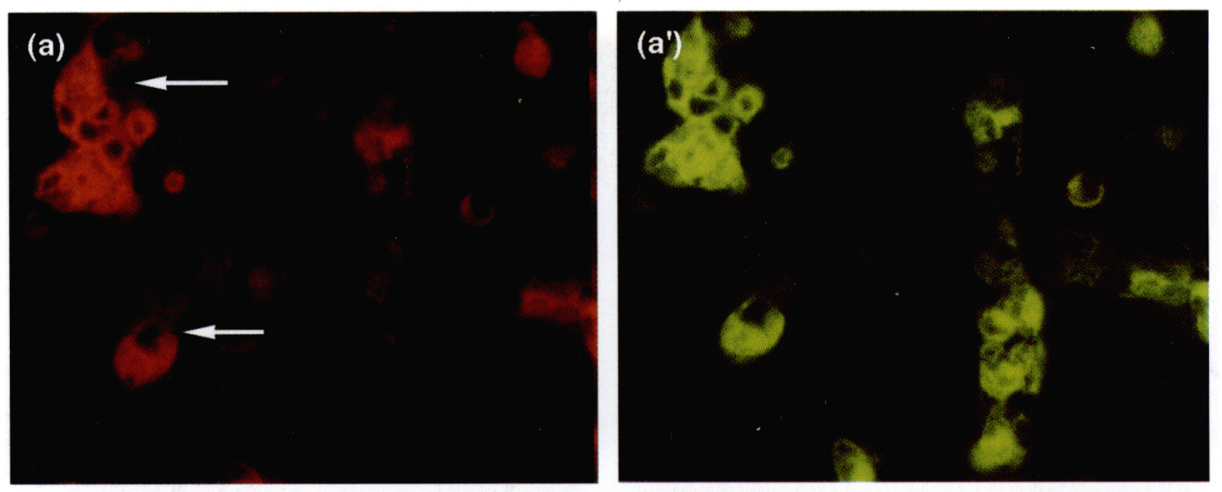

\section{(b)}

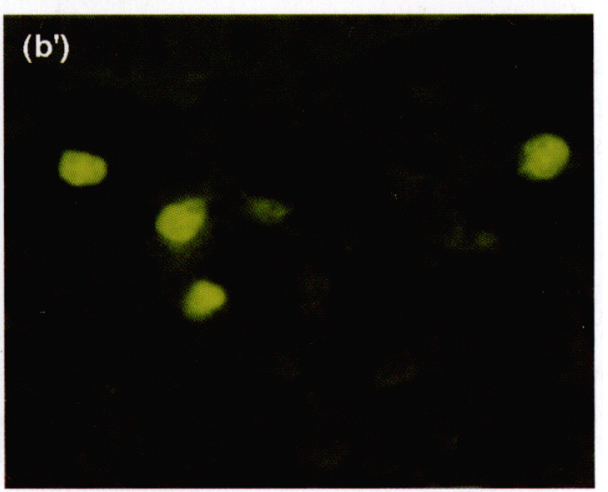

\section{(c)}

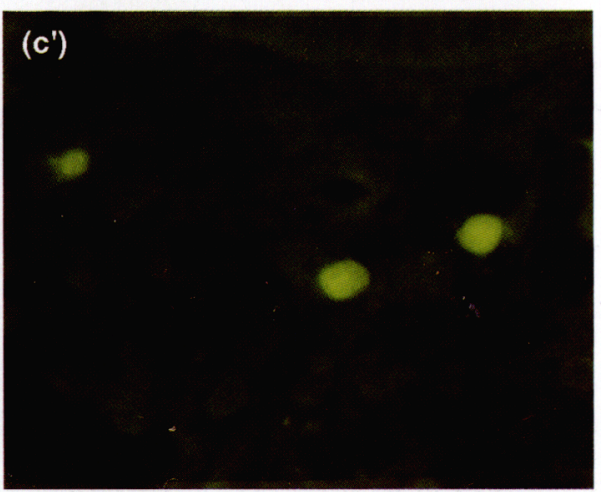

(d)

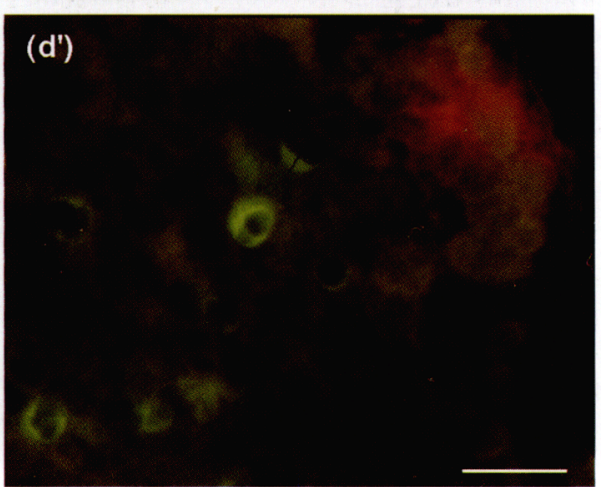

Fig. 2. Demonstration by dual immunolocalization of gelatinase $B$ production by migratory inflammatory cells in human endometrium. (a) Polymorphonuclear leucocytes (PMNs) in blood vessels (arrows) in premenstrual endometrial stromal tissue immunostained for PMN-elastase with Texas-Red; (b) macrophages in premenstrual endometrium immunostained for monoclonal antibody CD68; (c) eosinophils in menstrual endometrium immunostained for human eosinophil cationic protein; (d) mast cells in menstrual endometrium immunostained for human mast cell-tryptase. ( $\left.a^{\prime}\right)-\left(d^{\prime}\right)$ are the same fields as (a)-(d), respectively, immunostained for gelatinase B with fluorescein isothiocyanate. Note the intracellular expression of gelatinase B by PMNs, macrophages and eosinophils. (a') demonstrates cells positive for gelatinase B which represent PMNs as well as other cell types. Scale bar represents $40 \mu \mathrm{m}$. 


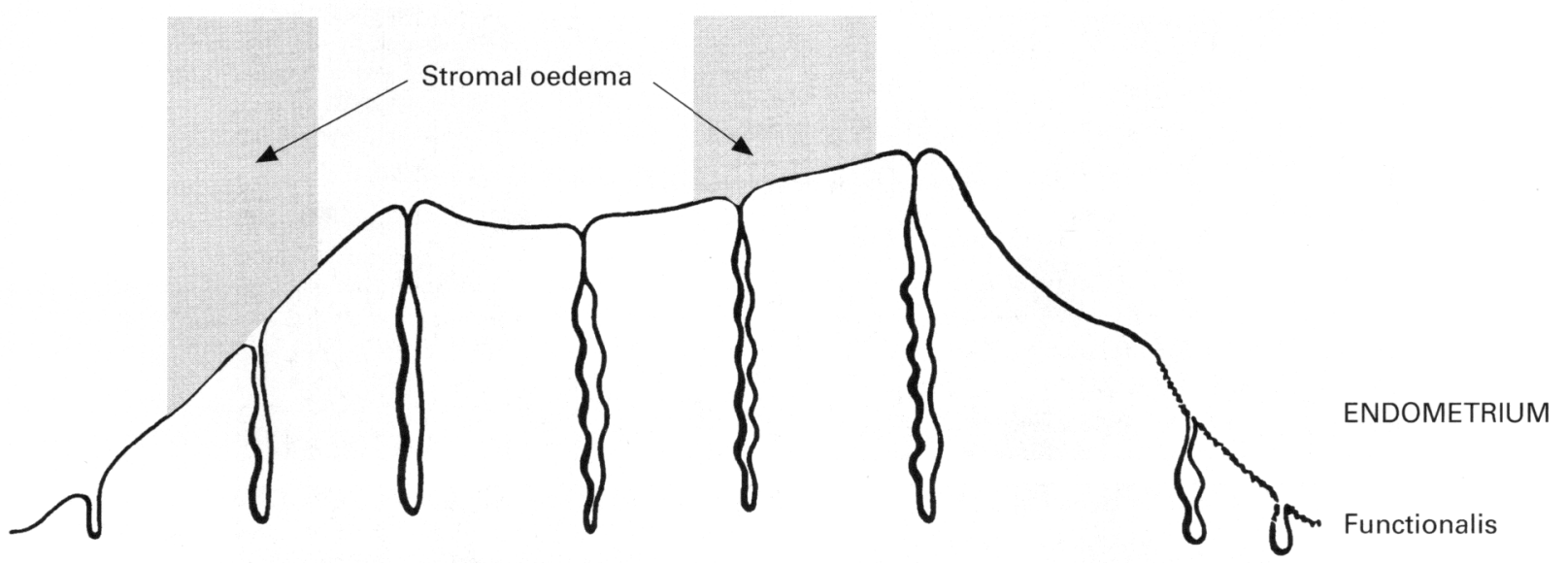

$008000008000000008000^{\circ} 08^{\circ} 00^{\circ} 808800808$ Basalis

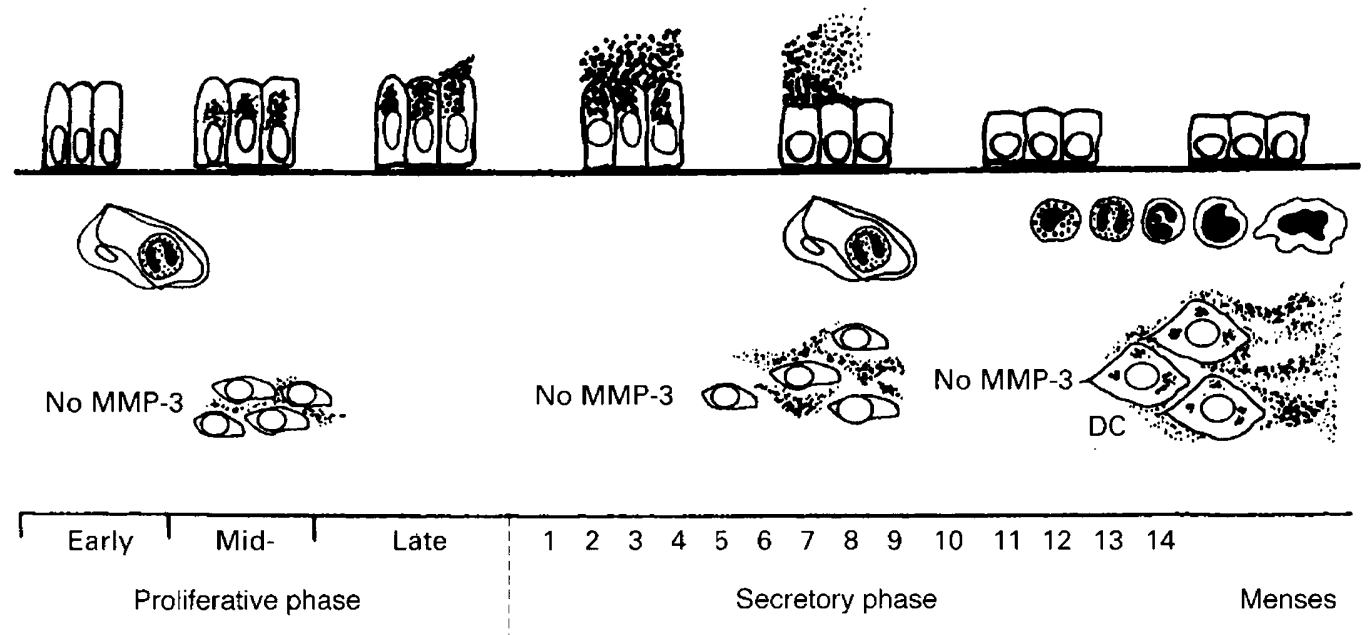

Fig. 3. Representation of the interrelationships between endometrial growth, gelatinase B (MMP-9) and stromelysin I (MMP-3) expression during the menstrual cycle. Note the temporal regulation of metalloproteinase production throughout the cycle, especially the prominent distribution of both enzymes during menstruation, a time coincident with the influx of neutrophils, macrophages and eosinophils. DC: decidual cells.

mid-proliferative and mid-secretory phases seems uncertain. It is of interest that the appearance of the enzyme at these times coincides with times of endometrial oedema. Stromelysin 1 also plays an important role in the activation of various metalloproteinase precursors, for example, procollagenase (Nagase et al., 1991) and progelatinase B (Ogata et al., 1992). However, at least in the study reported here, there is no evidence that gelatinase $B$ and stromelysin 1 occupy the same tissue or secretion environments, other than at menstruation.

Endometrial expression of mRNA for matrilysin and stromelysin-3 were shown to be pronounced during the proliferative, late secretory and menstrual phases, but were not detected during early or mid-secretory endometrium (Rodgers et al., 1993; Osteen et al., 1994). In contrast, mRNAs encoding collagenase and stromelysin 1 were found to be restricted to menstrual and perimenstrual specimens of human endometrium, with no detection between days 4 and 26 of the cycle (Hampton and Salamonsen, 1994). The detailed study by Rodgers et al. (1994) reported that expression of mRNA encoding gelatinase B was restricted to the late secretory and menstrual endometrium; there was no evidence for its expression by glandular epithelial cells during the mid-part of the cycle. The immunolocalization data of gelatinase B production by epithelial cells over the time course reported here were consistently supported by observations from 29 different specimens. It seems inevitable that the detection of enzyme protein by immunolocalization and mRNA by in situ hybridization will provide different information of the distribution of gelatinase B, not least because PMNs probably contain stored enzyme protein with negligible message. Our earlier report that cultured human endometrial stromal cells produced gelatinase $B$ when stimulated with phorbol myristate acetate, interleukin- 1 or tumour necrosis factor- $\alpha$ showed the 'potential' of the stromal cell to produce this enzyme in vitro (Rawdanowicz et al., 1994). However, our present in situ observations indicate that gelatinase $\mathrm{B}$ production by the stromal cell is not a major component of its proteinase phenotype throughout the cycle. 
The findings for gelatinase $\mathrm{B}$ and stromelysin 1 reported here, and previous reports of MMP expression (Rodgers et al., 1993, 1994; Osteen et al., 1994; Salamonsen et al., 1994) emphasize different functional roles for the matrix metalloproteinases during specific phases of the menstrual cycle. Only during menstruation, with its excessive degradation of the extracellular matrix, are most of the metalloproteinases found in the same tissue location. However, in the late secretory phase and at menstruation, the functionalis contains high numbers of PMNs, monocyte-macrophages and eosinophils (Finn, 1986; Hunt, 1994; Jeziorska et al., 1995), specific cell types providing not only a source of gelatinase B, but also providing stimulatory factors such as prostanoids and proinflammatory cytokines (Hunt, 1989; Rawdanowicz et al., 1994) which have the potential to promote metalloproteinase expression by resident stromal or epithelial cells (Birkedal-Hansen et al., 1993; Murphy and Reynolds, 1993). Although interactions between stromal and epithelial cells, mediated via steroidal regulation, may be important during the earlier phases of the menstrual cycle (Osteen et al., 1994), the introduction of PMNs, macrophages and other granulocytes, may well assume greater importance for proteinase production during menstruation (Jeziorska et al., 1995).

In conclusion, visual evidence is presented for the carefully timed synthesis and release of gelatinase B into "the glandular epithelial secretions and uterine fluid. Optimal atiounts of gelatinase B immunoreactivity were coincident with the periimplantation phase, although the precise functional role of gelatinase $B$ in the uterine fluid requires further study. PMNs, macrophages and eosinophils provided most of the gelatinase $\mathrm{B}$ at menstruation. In contrast, staining for stromelysin 1 was seen only in, and around, stromal cells; its production was restricted to microfocal locations at times coincident with stromal oedema. Both gelatinase B and stromelysin 1 were widely distributed in all menstruation specimens, and were particularly prominent on connective tissue stroma and basement membrane structures of blood vessels. Early proliferative specimens were devoid of both enzymes. The data provide further evidence supporting a role for metalloproteinases in endometiral biology, particularly the functional importance of specific cell types and the temporally regulated expression of these two metalloproteinases throughout the normal menstrual cycle.

The work was supported by the North West Regional Health Authority (D. E. Woolley), NIH Grant AR 39189 (H. Nagase) and the NH \& MRC of Australia (L. A. Salamonsen). The authors thank A. Butt for excellent technical assistance, M. Marsh and F. Hammond for tissue collection, and G. Kovacs and M. Barnett for providing tissue from their patients.

\section{References}

Aplin JD (1991) Glycans as biochemical markers of human endometrial secretory differentiation Journal of Reproduction and Fertility 92 525-541

Aplin JD, Seif MW, Graham RA, Hey NA, Behzad F and Campbell S (1994) The endometrial cell surface and implantation Annals of the New York Academy of Sciences 734 103-121

Birkedal-Hansen H, Moore WG, Bodden MK, Windsor LJ, Birkedal-Hansen B, DeCarlo A and Engler JA (1993) Matrix metalloproteinases: a review Crifical Reviews in Oral Biology and Medicine 4 197-250
Bischof P. Friedli E, Martelli M and Campana A (1991) Expression of extracellular matrix-degrading metalloproteinases by cultured human cytotrophoblast cells: effects of cell adhesion and immunopurification American Journal of Obstetrics and Gynecology 165 1791-1801

Finn CA (1986) Implantation, menstruation and inflammation Biological Reviews $61313-328$

Hampton AL and Salamonsen LA (1994) Expression of messenger ribonucleic acid encoding matrix metalloproteinases and their tissue inhibitors is related to menstruation Journal of Endocrinology 141 RI-R3

Hunt JS (1989) Cytokine networks in the uteroplacental unit: macrophages as pivotal regulatory cells Journal of Reproductive Immunology 16 1-17

Hunt J (1994) Immunologically relevant cells in the uterus Biology of Reproduction 50 461-466

Jeffrey JJ, Coffey RJ and Eisen AZ (I97I) Studies on uterine collagenase in tissue culture. II. Effect of steroid hormones on enzyme production Biochimica et Biophysica Acta 252 143-150

Jeziorska M, Haboubi NY, Schofield PF, Ogata Y, Nagase H and Woolley DE (1994) Distribution of gelatinase B (MMP-9) and type IV collagen in colorectal carcinoma International journal of Colorectal Disease 9 14I-148

Jeziorska M, Salamonsen LA, Woolley DE (1995) Mast cell and eosinophil distribution and activation in human endometrium throughout the menstrual cycle Biology of Reproduction 53 312-320

Lees M, Taylor DJ and Woolley DE (1994) Mast cell proteinases activate precursor forms of collagenase and stromelysin, but not of gelatinase $\mathrm{A}$ and B European Journal of Biochemistry $223 \quad 171-177$

Librach CL, Werb Z, Fitzgerald ML, Chiu K, Corwin NM, Esteves RA, Grobelny D, Galardy R, Damsky CH and Fisher SJ (1991) 92-kD type IV collagenase mediates invasion of human cytotrophoblasts Joumal of Cell Biology 113 437-449

Marbaix E, Donnez J, Courtoy PJ and Eeckhout Y (1992) Progesterone regulates the activity of collagenase and related gelatinases $A$ and $B$ in human endometrial explants Proceedings of the National Academy of Sciences USA $\mathbf{8 9}$ $11789-11793$

Marbaix E, Kokorine I, Courtoy PJ and Eeckhout Y (1995) Collagénases et métalloprotéases apparentées: un role essentiel dans le déclenchement de la menstruation? Médecine Sciences 11 126I-1269

Martelli M. Campana A and Bischof P (1993) Secretion of matrix metalloproteinases by human endometrial cells in vitro Journal of Reproduction and Fertility 98 67-76

Matrisian LM (1990) Metalloproteinases and their inhibitors in matrix remodelling Trends in Genetics 6 121-125

Matrisian LM, Gaire M, Rodgers WH and Osteen KG (1994) Metalloproteinase expression and hormonal regulation during tissue remodelling in the cycling human endometrium. In Extracellular Matrix in the Kidney. Contributions to Nephrology pp 94-100 Eds H Koide and T Hayashi. Karger, Basel

Morodomi T, Ogata Y, Sasaguri Y, Morimatsu M and Nagase H (1992) Purification and characterisation of matrix metalloproteinase-9 from U937 monocyte leukaemia and HT1080 fibrosarcoma cells Biochemical Journal $\mathbf{2 8 5}$ 603-611

Murphy LJ and Ballejo G (1994) Growth factor and cytokine expression in the endometrium. In Molecular Biology of the Female Reproductive System PP 345-378 Ed. JK Findlay. Academic Press, San Diego

Murphy G and Reynolds JJ (1993) Extracellular matrix degradation. In Connective Tissue and its Heritable Disorders: Mollecular and Genetic Aspects pp 287-316 Eds PM Royce and B Steinman. Wiley-Liss Inc., New York

Nagase H, Ogata Y, Suzuki K, Enghild JJ and Salvesen G (1991) Substrate specificities and activation mechanisms of matrix metalloproteinases Biochemical Society Transactions 19 715-718

Noyes RW, Hertig AT and Rock J (1950) Dating the endometrial biopsy Fertility and Sterility $13-25$

Ogata Y, Enghild JJ, Salvesen G and Nagase H (1992) Matrix metalloproteinase 3 (stromelysin) activates the precursor for the human matrix metalloproteinase 9 Journal of Biological Chemistry 267 3581-3584

Okada Y, Nagase H and Harris EDJ (1986) A metalloproteinase from human rheumatoid synovial fibroblasts that digests connective tissue matrix components: purification and characterization Joumal of Biological Chemistry 261 $14245-14255$

Osteen KG, Rodgers WH, Gaire M, Hargrove JT, Gorstein F and Matrisian LM (1994) Stromal-epithelial interaction mediates steroidal regulation of metalloproteinase expression in human endometrium Proceedings of the National Academy of Sciences USA 91 10 129-10 133

Rawdanowicz TJ, Hampton L, Nagase H, Woolley DE and Salamonsen LA (1994) Matrix metalloproteinase production by cultured human endometrial 
stromal cells: identification of interstitial collagenase, gelatinase- $A$ gelatinase- $B$, and stromelysin- 1 and their differential regulation by interleukin- $1 \alpha$ and tumor necrosis factor- $\alpha$ Journal of Clinical Endocrinology 79 530-536

Rodgers WH, Osteen KG, Matrisian LM, Navre M, Giudice LC and Gorstein F (1993) Expression and localization of matrilysin, a matrix metalloproteinase, in human endometrium during the reproductive cycle American Journal of Obstetrics and Gynecology 168 253-260

Rodgers WH, Matrisian LM, Giudice LC, Dsupin B, Cannon P, Svitek C, Gorstein $\mathrm{F}$ and Osteen KG (1994) Patterns of matrix metalloproteinase expression in cycling endometrium imply differential functions and regulation by steroid hormones Journal of Clinical Investigation 94 946-953

Salamonsen LA, Nagase H and Woolley DE (1991) Production of matrix metalloproteinase 3 (stromelysin) by cultured ovine endometrial cells journal of Cell Science 100 381-385

Salamonsen LA, Nagase H, Suzuki R and Woolley DE (1993) Production of matrix metalloproteinase $\mathrm{I}$ (interstitial collagenase) and matrix metalloproteinase 2 (gelatinase A: $72 \mathrm{kDa}$ gelatinase) by ovine endometrial cells in vitro: different regulation and preferential expression by stromal fibroblasts Joumal of Reproduction and Fertility 98 583-589

Salamonsen LA, Suzuki R, Nagase H and Woolley DE (1994) Matrix metalloproteinases: a role in implantation? In Endocrinology of Embryo-Endometrium Interactions pp 365-377 Eds SR Glasser, J Mullholland and A Psychoyos. Plenum Press, New York
Sato T, Ito A, Mon Y, Yamashita K, Hayakawa T and Nagase H (1991) Hormonal regulation of collagenolysis in uterine cervical fibroblasts. Modulation of synthesis of procollagenase, prostromelysin and tissue inhibitor of metalloproteinases (TIMP) by progesterone and estradiol-17-beta Biochemical Journal 275 645-650

Schatz F, Papp C, Toth-Pal E and Lockwood CJ (1994) Ovarian steroidmodulated stromelysin- 1 expression in human endometrial stromal and decidual cells Journal of Clinical Endocrinology and Metabolism $7 \mathbf{8}$ 1467-1472

Siri A, Knäuper V, Veirana N, Caocci F, Murphy G and Zardi L (1995) Different susceptibility of small and large human tenascin- $\mathrm{C}$ isoforms degradation by matrix metalloproteinases Journal of Biological Chemistry 270 8650-8654

Tabibzadeh SS (1991) Human endometrium: an active site of cytokine production and action Endocrinology Review 12 272-290

Tetlow LC, Lees M, Ogata Y, Nagase H and Woolley DE (1993) Differential expression of gelatinase B (MMP-9) and stromelysin-1 (MMP-3) by rheumatoid synovial cells in vitro and in vivo Rheumatology International 13 $53-59$

Woessner JF (1991) Matrix metalloproteinases and their inhibitors in connective tissue remodelling FASEB Journal 5 2145-2154

Wu JJ, Lark MW, Chun LE and Eyre DR (1991) Sites of stromelysin cleavage in collagen type II, IX and, type XI of cartilage Journal of Biological Chemistry $2665625-5628$

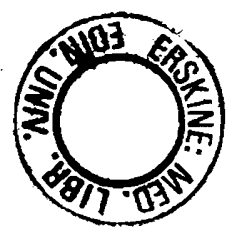

